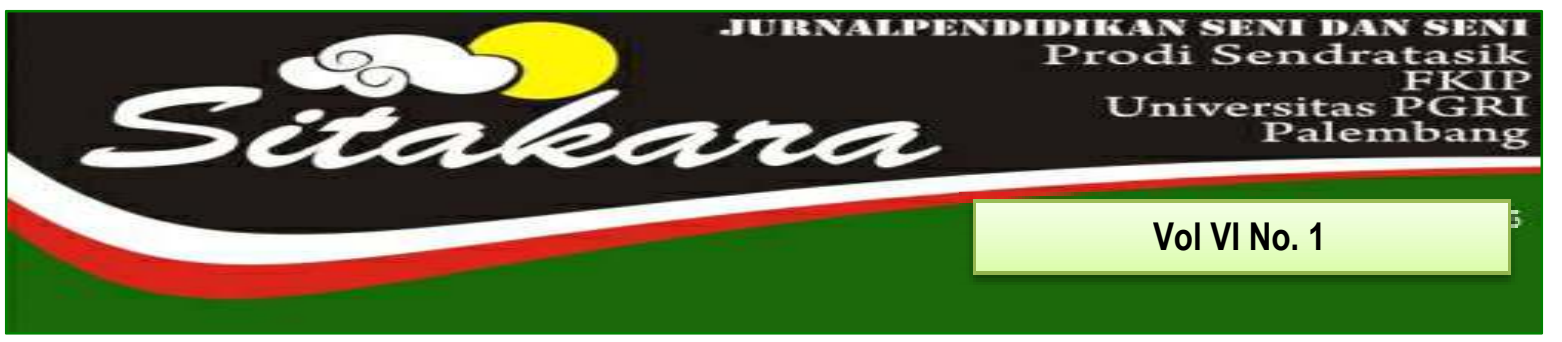

PERTUNJUKAN SOLIS MARIMBA DENGAN REPERTOAR THE VARIANTIONS ON THEME (FROM THE MALAY'S "PUCUK PISANG")

(Fery Herdianto)

BUKIT SIGUNTANG DALAM PENGEMBANGAN KONSEP RUANG KOREOGRAFI $\quad$ 13-26 LINGKUNGAN TARI

(Rully Rochayati, Eva Dina Chairunisa)

APLIKASI SIBELIUS SEBAGAI MEDIA PEMBELAJARAN DALAM MENULIS NOTASI MUSIK BERMAS

(Dedy Firmansyah \& Nugroho NAD)

PENGARUH MODEL PEMBELAJARAN EXPLICIT INSTRUCTION PADA 40-54 PEMBELAJARAN TARI DAERAH

(Treny Hera \& Efita Elvandari)

SIMBOLISASI ORNAMEN NAGA PADA PEMBATAS JALAN DI PALEMBANG (Decky Kunian \& A.Heryanto)

PENGARUH MODEL PEMBELAJARAN INSIDE-OUTSIDE-CIRCLE (IOC) TERHADAP WRITING SKILL DALAM TEKS MENULIS DRAMA DI SMP SETIA NEGARA PALEMBANG

(Sri Wahyu Indrawati \& Yuspar Uzer)

PEMANFAATAN TEKNOLOGI MULTIMEDIA DALAM PEMBELAJARAN MUSIK DI $79-87$ SMP N 1 PALEMBANG

(Novdaly Fillamenta \& Yuliza Aryani)

BENTUK PENYAJIAN ORKES GAMBUS SANGGAR MOZAIG PADA ACARA PERNIKAHAN ADAT ARAB PALEMBANG

(Auzy Madona Adoma)

PENINGKATAN KEMAMPUAN MEMBACA TEKS DRAMA DENGAN 100-111 MENGGUNAKAN METODE SPEED READING PADA PEMBELAJARAN BAHASA INDONESIA UNTUK SISWA SMPN 16 PALEMBANG (Wandiyo)

PELAKSANAAN EVALUASI PEMBELAJARAN SENI BUDAYA DI SMP 1 JEKULO 112-123 KUDUS PADA MASA PANDEMI COVID-19

M.Panji Wahyu Mukti \& Wahyu Lestari 
1. Naskah berbahasa Indonesia bertemakan Seni Budaya yang meliputi hasil penelitian pengajaran seni budaya, cabang seni, dan kebudayaan.

2. Naskah harus asli dan belum pernah dimuat dalam media lain. Naskah dapat berupa hasil penelitian perorangan atau kelompok.

3. Naskah ditulis dengan cara-cara yang sesuai dengan ketentuan penulisan artikel ilmiah menggunakan bahasa Indonesia yang baku, berupa ketikan, beserta soft line dalam CD-RW atau dengan mengirimkan email pada redaksi Jurnal SITARARA dengan alamat email: jurnalsitakarasendratasik@yahoo.com, spasi 1,5 jenis huruf Arrial Narrow ukuran 12, dengan panjang naskah antara 8-15 halaman pada kertas A4.

4. Artikel hasil penelitian memuat:

JUDUL

Nama Penulis

Abstrak

A. Pendahuluan

B. METODE PENELITIAN

C. HASIL DAN PEMBAHASAN

D. SIMPULAN
: XXX (HURUF KAPITAL)

: (disertai jabatan dan institusi)

: (Bahasa Indonesia yang memuat 100150 kata diikuti kata kunci, dengan jenis huruf Arrial Narrow dan ukuran huruf 11 spasi tunggal serta dicetak miring)

: (Memuat latar belakang masalah, tinjauan pustaka secara ringkas, masalah penelitian dan tujuan penelitian)

: (Berisi simpulan)

5. Artikel kajian konseptual memuat:

JUDUL

Nama Penulis

Abstrak

\section{: XXX (HURUF KAPITAL)}

: (disertai jabatan dan institusi)

: (Bahasa Indonesia yang memuat 100150 kata diikuti kata kunci, dengan jenis huruf Arrial Narrow dan ukuran huruf 11 serta dicetak miring)

PENDAHULUAN
: (Memuat latar belakang masalah, tinjauan pustaka secara ringkas, masalah penelitian dan tujuan penelitian) 
Sub Judul

Sub Judul

SIMPULAN

DAFTAR PUSTAKA
: Sesuai dengan kebutuhan (tanpa numbering)

: (Berisi simpulan dan saran)

: (Berisi pustaka yang dirujuk dalam uraian naskah

6. Referensi sumber dalam teks artikel ditulis dengan menggunakan side note, contoh: (Jalalluddin, 1991:79); (Taufik, 2005;350); (Hamid dan Madjid, 2011:43). Sementara penulisan daftar pustaka disusun dengan ketentuan. Nama Pengarang. Tahun Terbit. Judul (dicetak miring). Kota Terbit: Nama Penerbit. Contoh: Koentjaraningrat. 2010. Manusia dan Kebudayaan Di Indonesia. Jakarta: Djambatan.

Daftar pustaka hanya memuat pustaka/sumber yang dirujuk dalam uraian dan disusun menurut abjad, tanpa nomor urut.

7. Naskah yang dimuat akan disunting kembali oleh redaksi tanpa mengubah isinya.

8. Naskah yang ditolak (tidak bisa dimuat) akan dikirim kembali ke penulis dengan pemberitahuan tertulis dari redaksi atau alamat email.

9. Penulis yang naskahnya dimuat akan mendapatkan 1 (satu) majalah nomor yang bersangkutan.

10. Contact Person: Treny Hera (085357344704) dan Mainur (081373165553). 


\title{
BENTUK PENYAJIAN ORKES GAMBUS SANGGAR MOZAIG PADA ACARA PERNIKAHAN ADAT ARAB PALEMBANG
}

\author{
Oleh: \\ Auzy Madona Adoma \\ (Dosen FKIP Universitas PGRI Palembang) \\ Email: auzymadonaadoma@ymail.com
}

\begin{abstract}
ABSTRAK
Penelitian ini bertujuan untuk mendeskripsikan Bentuk Penyajian Orkes Gambus Sanggar Mozaig Pada Acara Pernikahan Adat Arab Palembang. Penelitian ini menggunakan metode penelitian diskriptif kualitatif. Objek penelitian dalam Objek dalam penelitian ini adalah Bentuk Penyajian Orkes Gambus Sanggar Mozaig Pada Acara Pernikahan Adat Arab Palembang. Metode pengumpulan data dilakukan dengan observasi, wawancara dan dokumentasi. Kebasahan data Perpanjangan Keikutsertaan, Ketentuan/Keajegan Pengamatan dan Triangulasi. Teknik analisis data menggunakan tiga tahapan teknik analisis observasi, wawancara dan dokumentasi. Hasil penelitian adalah kelompok musik gambus 16 llir ini tidak hanya mengajak warga keturunan arab saja untuk dapat menikmati kesenian ini tetapi juga warga melayu Palembang dan menjadi kesenian yang sifatnya global. Karena antara kebudayaan arab dan kebudayaan melayu mempunyai persamaan yang sangat dekat dari segi musik,pesan moral yang tergandung di dalam lagu yang dibawakan, kultur ramah-tamah yang di miliki,sifat religius yang sangat tinggi,dan sebagainya.
\end{abstract}

Kata Kunci: Bentuk Penyajian Musik, Gambus

\section{A. PENDAHULUAN}

Indonesia adalah negara dengan kekayaan budaya yang tak ada tandinganya di dunia. Memiliki Banyak Pulau yang terpencar, dibatasi Lautan luas, terdapat banyak suku bangsa yang menetap di Hutan, Pedesaan, GunungGunung dan Pesisir Pantai. Letak geografis yang terbentang luas dengan kekayaan alam melimpah tentulah mempengaruhi pola hidup dan budaya masing-masing suku yang ada seperti yang dikemukakan oleh (Firdaus, 2010: iii), dan hasil kebudayaan tersebut diwujudkan baik melalui benda-benda hasil karya manusia atau yang disebut kebudayaan fisik ataupun kebudayaan yang di tuangkan melalui kesenian seperti pendapat Honigman (2010:3-4), perwujudan kebudayaan adalah bendabenda hasil karya manusia, disebut pula kebudayaan fisik. Dimana wujud budaya ini hampir seluruhnya merupakan hasil fisik yaitu aktifitas perbuatan, dan karya 
semua manusia dalam masyarakat. Sifatnya paling konkret dan berupa benda-benda atau hal-hal yang dapat diraba, dilihat dan difoto yang berwujud besar ataupun kecil. Salah satu hasil dari kebudayaan fisik tersebut lah yang ditunjukkan oleh sebuah sanggar seni musik bernuansa Arab yang bernama sanggar Mozaig, dimana musik di sanggar tersebut merupakan hasil gabungan dari kebudayaan Arab dan masyarakat Kota Palembang, Musik Arabian yang dikemas sedemikian rupa, menggabungkan antara unsur tradisional dan modern, hal itu terlihat dari alat musik yang digunakan seperti oud atau gitar gambus tradisional yang dipadukan dengan gitar bass elektrik dan juga keyboard elektrik, kemasan atau penyajian musik tersebut diharapkan mampu menarik perhatian dan minat para kaum muda.

Berdasarkan beberapa penemuan sejarah yang ditemukan di Kota Palembang, terutama penemuan Prasasti Kedukan Bukit di sekitar daerah Karanganyar (tempat Museum Taman Purbakala Kerajaan Sriwijaya) menunjukan bahwa Palembang, sebagai pusat kerajaan Sriwijaya yang terkenal akan perdagangan laut antar bangsa.
Dari situlah awal masuknya bangsa lain dari berbagai belahan dunia seperti Cina, Arab, dan India ke Kota Palembang, Hal ini juga lah yang mempengaruhi sedikit banyaknya kesenian yang ada di Palembang itu sendiri, baik itu seni tari, rupa dan musik, salah satu contoh kesenian luar yang sampai sekarang masih ada di Kota Palembang itu sendiri adalah musik gambus yang dipengaruhi dari masuknya bangsa Arab ke Palembang.

Musik gambus itu sendiri pada awalnya merupakan suatu komposisi musik yang dihasilkan oleh alat musik berupa gitar gambus yang dimainkan dengan cara dipetik dan diiringi gendang, lirik-lirik yang terkandung dalam musik gambus itu sendiri bermacam-macam, baik menceritakan keadaan yang sedang terjadi, puji-pujian terhadap yang maha kuasa, maupun tentang perasaan hati seniman itu sendiri.

Palembang merupakan salah satu kota yang kebudayaannya masih terasa kental baik dari kesenian musik, tari, maupun rupa (kriya). Baik kesenian lokal maupun kesenian yang telah bercampur dengan kesenian dari luar. Kiranya kebudayaan yang kaya akan keanekaragaman ini mendapat perhatian 
yang serius agar tetap terjaga. Mengingat pengaruh era modern kebudayaan daerah setempat dianggap ketinggalan jaman dan hanya pada kalangan tertentu sehingga sebagian kalangan anak remaja tidak tahu bahkan meninggalkannya. Oleh karena itu, kebudayaan daerah perlu terus dibina dan dikembangkan, agar tetap bertahan.

Berdasarkan penjelasan diatas penulis tertarik untuk mengadakan penelitian guna mendapatkan informasi yang lebih jelas mengenai "Bentuk Penyajian Orkes Gambus Sanggar Mozaig Pada Acara Pernikahan Adat Arab Palembang."

\section{B. METODE PENELITIAN}

Metode pengumpulan data dilakukan dengan observasi, wawancara dan dokumentasi. Kebasahan data Perpanjangan Keikutsertaan, Ketentuan /Keajegan Pengamatan dan Triangulasi. Teknik analisis data menggunakan tiga tahapan teknik analisis observasi, wawancara dan dokumentasi.

\section{HASIL DAN PEMBAHASAN}

Musik gambus itu sendiri pada awalnya merupakan suatu komposisi musik yang dihasilkan oleh alat musik berupa gitar gambus yang dimainkan dengan cara dipetik dan diiringi gendang, lirik-lirik yang terkandung dalam musik gambus itu sendiri bermacam-macam, baik menceritakan keadaan yang sedang terjadi, puji-pujian terhadap yang maha kuasa, maupun tentang perasaan hati seniman itu sendiri (sumber: wawancara dengan Ali Murtado, 25 Desember 2016).

Pada pernikahan adat Arab Palembang itu sendiri yaitu pada malam hari acara hiburan, yang menyajikan musik gambus, semua tamu undangan di undang untuk meramaikan acara hiburan dengan ikut menari yang diiringi lantunan lagu-lagu bernuansa timur tengah .

Menurut keterangan Ali Murtado pada wawancara 25 Desember 2016 pertunjukan musik gambus bertujuan sebagai ungkapan rasa bahagia sepasang pengantin yang sedang melakukan pernikahan, serta memberitahukan kepada masyarakat bahwa sepasang pengantin yang sedang berjalan sudah sah melakukan akad nikah, selain itu pertujukan ini sebagai sarana hiburan, namun demikian pertunjukan musik gambus ini sudah menjadi budaya. Dimana setiap 
masyarakat keturunan Arab yang melakukan perkawinan sebagian besar atau bisa dikatakan hampir seluruhnya akan melakukan proses pertunjukan musik gambus tersebut,

Sanggar Mozaig pimpinan Ali Murtado merupakan salah satu sanggar seni musik bernuansa Timur tengah atau Arab yang berada di Kota Palembang yang berlokasi di Kelurahan 16 ilir Kecamatan llir Timur 1 Kota Palembang. Musik yang disajikan oleh sanggar Mozaig itu sendiri lebih dikenal dengan musik gambus. Musik tradisional arab yang biasanya menyanyikan lagu sholawat, khosidah dan lagu-lagu dari daerah asal musik tersebut yaitu timur tengah.

Berdasarkan hasil wawancara dengan Ali Murtado (Ketua Sanggar Mozaig), jumlah pemain music gambus dalam pertunjukan pertunjukan music gambus berjumlah 7 orang, itu merupakan tim pemusik yang seutuhnya, terdiri dari 4 pemain alat music instrument dan 3 pemain music perkusi.

Bentuk formasi pemain musik gambus membentuk 4 barisan yang memanjang di depan pemain musiknya, yakni 1 orang baris pertama sebagai vokalis sekaligus pemain oud(gambus) dan 3 orang baris kedua yang terdiri dari 2 pemain keyboard dan 1 pemain gitar bass, di barisan ke orang berbars dari depan sampai belakang menghadap samping mengarah ke pemain keyboard yaitu terdiri dari pemain darbuka, dan pemain tamborin dan di barisan terkhir yakni pemain drum yang menghadap ke depan.

Struktur Bentuk Penyajian Orkes Gambus Sanggar Mozaig Pada Acara Pernikahan Adat Arab Palembang adalah sebgai berikut:

1) Persiapan

- Mempersiapkan alat - alat seperti:

a. Menyiapkan Sound system

b. Menyiapkan dan meyusun Alat -alat musik gambus

C. Tata pentas

d. Cek sound

2) Pembukaan

Pada bagian ini pemain musik gambus memainkan lagu instrumental tanpa vocal sebanyak 2 lagu yang berjudul Lain Fakaruni dan Al Filaila, dan dimulai pukul 20.00 s/d 20.30 WIB. Pada bagian ini para penari gambus dan tamu undangan yang hendak meramaikan blum di perbolehkan menari, di karenakan musik yang di 
sajikan pada pembukaan ini merupakan lagu khusus bagi para pemain musik kepada tamu undangan atau penonton agar terfokus dalam menikmati musik inrumental yang di sajkan oleh sanggar Mozaig,

3) Acara Inti

Pada acara inti pemain musik gambus memainkan lagu -lagu bertempo cepat

Dengan tujuan agar lebih meriah, dan juga memacuh antusias penonton, agar ikut menari dan suasana pun menjdi lebih meriah. Lagu-lagu yan di mainkan pada acara memiliki tiga pola tabuh yang berbeda yaitu zaife, sarah , dan zafin. Ketiganya memiliki perbedaan yang signifikan. Pola tabuh zaife memiliki kelebihan tersendiri yang membuat antusias untuk ikut menari, di karenakan pola ini bertempo cepat dan sederhana sehinngga memudahkan bagi para penonton yang ikut menari bersama penari sanggar mozaig. Sedangkan pukulan Zafin mengiringi lagu-lagu gembirapada saat pertunjukan musik gambus, seperti lagu berbalas pantun. Pukulan Zafin adalah nada yang sering digunakan untuk mengiringi lagu-lagu pujian kepada nabi Muhammad SAW (sholawat). Tempo zafin lebih lambat dan tidak terlalu menghentak, sehingga juga digunakan dalam mengiringi lagu-lagu Melayu. Pukulan sarah sedikit mirip dengan Zaife perbedanya pukulan Sarah lebih menghentak disbanding pukulan Zaife dan juga pada Sukat nya, pada pukulan Zaife menggunakan sukat $4 / 4$ sedangan pukulan Sarah menggunakan sukat $3 / 4$.

Sampai saat ini musik gambus masih di gemari oleh masyarakat Palembang keturunan Arab. Hal ini terbukti darimasih seringnya di perunjukkan musik gambus pada acara pernikahan, khitanan, dan penyambutan tamu istimewa.

\section{4) Acara Bebas}

Untuk lebih meramaikan musik gambus pada acara pernikhan adat Arab

Palembang, penonton di perbolehkan untuk menyumbangkan sebuah lagu dan diiringi oleh pemain musik gambus. Lagu yang dinyanyikan oleh penonton pada acara bebas ini antara lain lagu Melayu, Dangdut, dan Bollywood.

\section{5) Penutup}

Pada bagian penutup pemain musik gambus menyanyikan lagu sholawat yang berjudul Sholatum Sallamil mubbin 
sambil menutup acara dengan ucapan salam penutup.

Menurut Ali Murtado pada wawancara 25 Desember 2016, alat musik yang digunakan dalam pertunjukan Musik Gambus Sanggar Mozaig Pada Acara Pernikahan Adat Arab Palembang adalah alat musik oud (gambus), keyboard 1, keyboard 2, gitar bass, darbuka, tamborin dan drum.

\section{1) Oud}

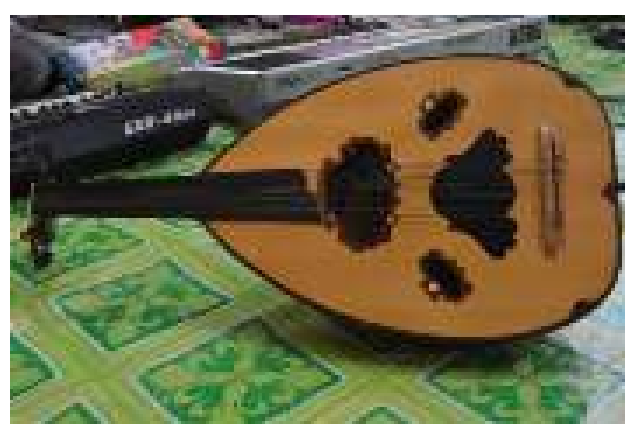

Gambar 1 : Oud (Foto : Naufal, 2016)

Oud(Gambus) yang digunakan oleh sanggar mozaig memiliki 12 senar, tanpa fret biasa di sebut fretless dengan tuning sebagai berikut:

- senar 1 dan 2 nada C

- senar 3 dan 4 nada G

- senar 5 dan 6 nada D

- senar 7 dan 8 nada A

- senar 9 dan 10 nada $F$

- senar 11 dan 12 nada C
2) Keyboard 1

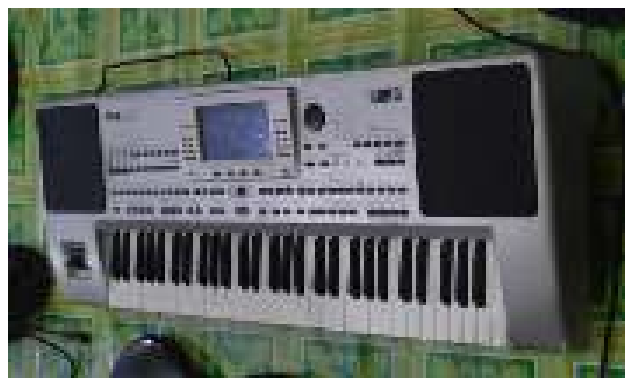

Gambar 2 : Keyboard 1 (Foto : Naufal, 2016)

Keyboard yang digunakan merupakan keybord berstandar Arabian musik,yang memiliki kelebihan karakteristik suara string yang tebal, satu note yang di tekan akan setara dengan suara dua belas biola yang di gesek secara bersamaan dan memiliki pengaturan untuk menurunkan satu nada menjadi sedikit fals yang disebut sikah untuk bisa memainkan tangga nada nada(scale) pada lagu lagu bernuansa Timur Tengah.

\section{3) Keyboard 2}

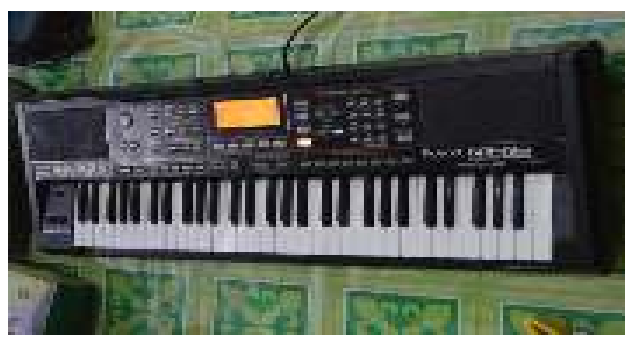

Gambar 3 : Keyboard 1 (Foto : Naufal, 2016)

Keybord 2 yang digunakan merupakan keybord berstandar Arabian 
musik memiliki karakteristik suara kanoun, mizmar, dan suling yang mirip dengan aslinya, dan memberi kesan suara nyata yang dimainkan dari alat music keybord ini.

4) Gitar Bass

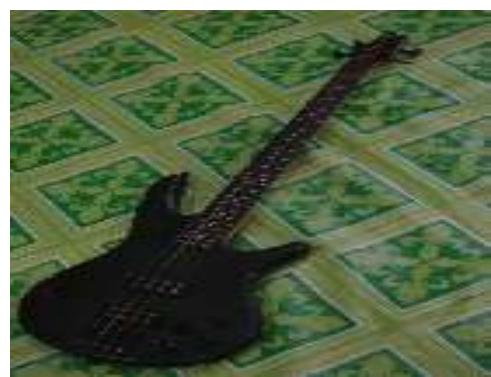

Gambar 4 : Gitar Bass (Foto : Naufal, 2016)

Gitar Bass yang digunakan merupakan gitar bass pada umunya yang menggunakan 4 senar dengan tuning sebagai berikut:

- Senar 1 nada G

- Senar 2 nada D

- Senar 3 nada A

- Senar 4 nada E

5) Darbuka

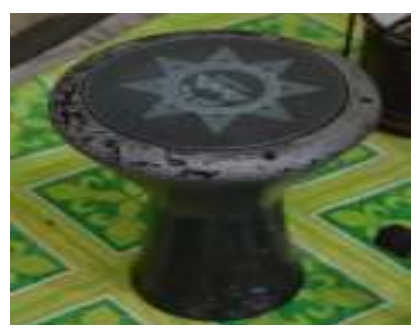

Gambar 5 : Darbuka (Foto : Naufal, 2016)

Darbuka yang digunakan terbuat dari batu keramik buatan Mesir, memiliki karateristik suara yang lebih nyaring di bandingkan darbuka yang terbuat stenlis, suara yang lebih nyaring berfungsi untuk variasi pukulan pada fiil in agar menampakan kesan Arabian music yang lebih terasa, peran alat music darbuka ini lebih dominan di bandingkan drum yang hanya berfungsi sebagai ritme pada music gambus yang di sajikan.

6) Tamborin

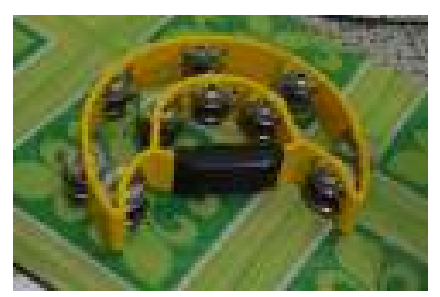

Gambar 6 : Tamborin (Foto : Naufal, 2016)

Tamborin yang digunakan memiliki anak simbal kecil, sehingga menimbulkan efek bunyi ketukan dan gemerincing.

\section{7) Drum}

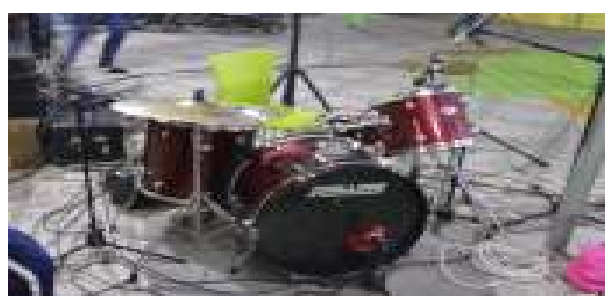

Gambar 7 : Drum (Foto : Naufal, 2016)

Drum yang digunakan ialah standar drum pada umunya yang terdiri dari: 
- Snare

- Bass drum

- Hi hat

- Crash symbal

- $\quad$ Mid tom

- Low tom.

Selanjutnya jumlah pemain musik gambus yang sering digunakan dalam acara pernikahan adat pernikahan arab adalah 7 orang. Dengan pembagiannya, yakni:

1) Satu orang penyanyi serta memainkan oud(gambus) sebagai pengisi vocal yang melantunkan lagu serta memainkan melodi dari alat musik gambus secara unison dengan suara vocal. Pemain oud juga berperan sekali pada awal lagu, karena setiap lagu bernuansa Arab pasti di awali dengan oud.

2) Pemain keyboard dimainkan dua orang. Pada keyboard satu menigisi suara string yang setara dengan 12 biola yang di gesekkan secara bersamaan (watariyat) sebagai pengganti suara biola, sedangan pemain keyboard 2 mengisi suara lead melodi menggunakan suara suling, kanoun, dan mizmar. Serta berfungsi sebagai rhythm dengan memainkan akor pada lagu.

3) pemain gitar bass pada music gambus sebagai pedoman akor, suara bass yang memberikan kemudahan bagi pemain alat music lain dan menjaga akor agar tetap satu irama dan juga sebagai pengatur tempo yang selalu irama dengan ketukan bass drum.

4) Pemain darbuka pada music gambus sebagai pengisi dari tempo drum. Yang di mainkan satu orang

5) Pemain tamborin pada music gambus juga sebagai penjaga tempo dan memberikan efek suara yang gemerincing.

6) Pemain drum pada music gambus sebagai pola dasar tabuh (umak).

Secara umum pemain musik gambus ini dikelompokkan menjadi 2 (tiga) bagian, yaitu:

1) Pemain musik melodis.pada music gambus harus mengetahui tangga nada yang digunakan pada lagu bernuansa Arab, ada 5 tangga nada 
wajib yang biasa dimainkan oleh pemain music gambus sanggar mozaig pada pertunjukkan gambus, yaitu hijaz, bayati, ross, dan nahwand

2) Pemain music ritmis pada music gambus wajib mengetahui pola tabuh yang digunakan pada music gambus, ada 3 pola tabuh yang wajib digunakan pada pertunjukan music gambus, yaitu masri, zaifeh, dan sarah.

- Keunikan pada music gambus ini terlihat dari adanya tangga nada dan pola tabuh yang khusus dalam penyajiannya.

Untuk interval atau tangga nada yang digunakan adalah Tangga nada Arab yang disebut juga denga maqam adalah system melodi yang digunakan dalam music tradisional arab. Kata maqam dalam bahasa Arab bearti tempat, lokasi atau posisi. Maqam Arab adalah adalah teknik improvisasi yang mendefinisikan nada, pola, dan pengembangan karya music yang unik pada music Arab.

Maqam Arab didasarkan pada skala music yang terdiri dari 7 nada yang sama pada oktaf. Skala maqam dalam music tradisional Arab tidak didasarkan pada sistem pada dua belas nada musik yang sama seperti halnya dalam musik Barat modern. Maqam yang sering digunakan oleh pemain musik gambus ada 4, yaitu:

1) Bayati

Maqam bayati memiliki interval sebagai berikut:

$3 / 4-3 / 4-1-1-1 / 2-1-1$

2) Hijaz

Maqam hijaz memiliki interval seagai berikut

$1 / 2-1 \frac{1}{2}-1 / 2-1-1 / 2-1-1$

3) Ross

Maqam ross memiliki interval sebagai berikut:

$1-3 / 4-3 / 4-1-1-3 / 4-3 / 4$

4) Nahwand

Maqam nahwand memiliki interval sebagai berikut:

$1-1 / 2-1-1-1 / 2-1-1$

Dalam tangga nada mimiliki 7 jarak nada (interval) yang sedikit berbeda pada tangga nada barat, perbedaan terletak pada 1 nada yang turun $1 / 4$ dari nada aslinya yang disbut dengan sikah.

\section{SIMPULAN}

Penelitian ini bertujuan untuk mengetahui bagaimana bentuk penyajian orkes gambus sanggar Mozaig pada 
acara pernikaha adat Arab Palembang.

Dalam penelitian ini terdapat 4 indikator yang diteliti yaitu pemain musik gambus, alat musik yang digunakan, tangga nada yang digunakan beserta syair lagu yang dinyanyikan.

Pengamatan yang dilakukan yaitu dengan mengadakan observasi, wawancara dan dokumentasi pada saat proses pertunjukan berlangsung. Dari hasil observasi dan wawancara, di dapat rata-rata lebih banyak jawaban yang bisa terjawab maka dapat dikategorikan pengamatan berjalan dengan baik dan sesuai dengan indikator. Sedangkan hasi lembar wawancara, dan dikategorinya juga baik dan sesuai dengan indikator yang dijadikan poin-poin dalam wawancara. Dengan kata lain selama pertunjukan berlangsung, semua berjalan dengan baik dan lancar wawaupun masih terdapat kekurangankekurangan. Musik gambus adalah musik yang dalam permainanya menggunakan alat musik gambus(oud), keyboard, gitar bass, darbuka, tamborin, dan drum. Musik gambus ini biasanya dipertunjukkan pada acara pernikahan adat Arab.. Bapak Ali Murtado merupakan salah satu seniman yang masih tetap gigih untuk mempertahankan kesenian tradisonal dengan campuran modern, agar lebih menarik perhatian kaum muda.

Dalam penyajiannya, pemain musik gambus memainkan lagu instrumental tanpa vocal sebanyak 2 lagu yang berjudul Lain Fakaruni dan Al Filaila, dan dimulai pukul $20.00 \mathrm{~s} / \mathrm{d}$ 20.30 WIB. Pada bagian ini para penari gambus dan tamu undangan yang hendak meramaikan blum di perbolehkan menari, di karenakan musik yang di sajikan pada pembukaan ini merupakan lagu khusus bagi para pemain musik kepada tamu undangan atau penonton agar terfokus dalam menikmati musik inrumental yang di sajikan oleh sanggar Mozaig, Pada acara inti pemain musik gambus memainkan lagu -lagu bertempo cepat dengan tujuan agar lebih meriah, dan juga memacuh antusias penonton, agar ikut menari dan suasana pun menjdi lebih meriah. Lagu-lagu yan di mainkan pada acara memiliki tiga pola tabuh yang berbeda yaitu zaife, sarah, dan zafin. Ketiganya memiliki perbedaan yang signifikan. Pola tabuh zaife memiliki kelebihan tersendiri yang membuat antusias untuk ikut menari, di karenakan pola ini bertempo cepat dan 
sederhana sehinngga memudahkan bagi para penonton yang ikut menari bersama penari sanggar mozaig. Sedangkan pukulan Zafin mengiringi lagu-lagu gembirapada saat pertunjukan musik gambus, seperti lagu berbalas pantun. Pukulan Zafin adalah nada yang sering digunakan untuk mengiringi lagulagu pujian kepada nabi Muhammad SAW (sholawat). Tempo zafin lebih lambat dan tidak terlalu menghentak, sehingga juga digunakan dalam mengiringi lagu-lagu Melayu. Pukulan sarah sedikit mirip dengan Zaife perbedanya pukulan Sarah lebih menghentak disbanding pukulan Zaife dan juga pada Sukat nya, pada pukulan Zaife menggunakan sukat 4/4 sedangan pukulan Sarah menggunakan sukat $3 / 4$. Untuk lebih meramaikan musik gambus pada acara pernikhan adat Arab Palembang, penonton di perbolehkan untuk menyumbangkan sebuah lagu dan diiringi oleh pemain musik gambus. Lagu yang dinyanyikan oleh penonton pada acara bebas ini antara lain lagu Melayu, Dangdut, dan Bollywood. Pada bagian penutup pemain musik gambus menyanyikan lagu sholawat yang berjudul Sholatum
Sallamil mubbin sambil menutup acara dengan ucapan salam penutup.

Berdasarkan hasil wawancara dengan Ali Murtado bahwa, musik gambus pada acara pernikahan adat Arab Palembang dalam penyajiannya menggunakan alat musik gamubus(oud), keyboard, gitar bass, darbuka,tamborin, dan drum. Sedangkan jumlah pemain musik gambus adalah 7 orang, yakni dengan pembagian 4 pemain musik melodis dan 3 pemain musik ritmis musik gambus pada saat acara adat perkawinan adalah pola tabuhan zaife dan sarah dan zafin, dengan masingmasing bertugas sebagai pola umak dan ningkah.

Tangga nada Arab yang disebut juga denga maqam adalah system melodi yang digunakan dalam music tradisional arab. Kata maqam dalam bahasa Arab bearti tempat, lokasi atau posisi. Maqam Arab adalah adalah teknik improvisasi yang mendefinisikan nada, pola, dan pengembangan karya music yang unik pada music Arab. Maqam Arab didasarkan pada skala music yang terdiri dari 7 nada yang sama pada oktaf. Skala maqam dalam music tradisional Arab tidak didasarkan pada sistem pada dua belas nada musik yang sama seperti 
halnya dalam musik Barat modern. bayati, hijaz, ross dan nahwand sebagai Maqam yang sering digunakan oleh dasar melodi pada lagu-lagu gambus. pemain musik gambus ada 4, yaitu

\section{Daftar Pustaka}

Adnan, Hasyim. 2010. Jenis Alat Musik Tradisional, Jakarta: Trias yoga kreasindo.

Arikunto, Suharsimi. 1998. Prosedur Penelitian Suatu Pendekatan Praktek. Jakarta: Rineka Cipta.

Firdaus, Iman. 2010. Pesta Adat Pernikahan di Nusantara. Jakarta: Multi kreasi Satudelapan.

Moleong, J. Lexy. 2014. Metodologi Penelitian Kualitatif. Bandung: PT. Remaja Rosdakarya.

Pemerintah Provinsi Sumatera Selatan. 2014. Musik Etnik Sumatera Selatan. (laporan buku). Palembang: Dinas Pendidikan Sum-Sel.

Sartono. 2013. Terampil Bermusik. Palembang: FKIP Universitas PGRI Palembang.

Sedyawati, Edi. 1981. Pertumbuhan Seni Pertunjukan. Jakarta: Sinar Harapan.

Sudartati, Yulie. 2012. Pengantar Kebudayaan Sumatera Selatan. Palembang: FKIP Universitas PGRI Palembang.

Sugiyono. 2011. Metode Penelitian Kuantitatif, Kualitatif dan R\&D. Bandung: Alfabeta.

Sugiyono. 2014. Memahami Penelitian Kualitatif. Bandung: Alfabeta. 